behaviour is unpredictable; tumours with increased malignant potential, by virtue of size and cytology, being termed atypical carcinoids. In addition to positive staining with routine epithelial and neuroendocrine markers, they usually express CEA but not $\$ 100$. Although commonly presenting as a primary lesion, metastases are not unusual and silent primary tumours have been described. ${ }^{1}$ Neurological complications are present in $40 \%$ of metastatic carcinoids and true central nervous system metastases have been documented both within the brain and spinal cord. ${ }^{2}$

Primary paragangliomas of the cauda equina are well described ${ }^{3}$ and, although malignant behaviour is rare, metastatic spread has been documented. ${ }^{4}$ Nuclear atypia and necrosis are unusual features. Positive staining for cytokeratin is uncommon and has not been reported for CEA to our knowledge. The supporting sustentacular cells are classically $\$ 100$ positive, although they are not always present. ${ }^{5}$

Pituitary carcinomas are a well recognised albeit rare entity. Generalised spread has been reported $^{6}$ although central nervous system spread is more common. Metastasis to the cauda equina has been documented. ${ }^{7}$ Most carcinomas are histologically identical to adenomas; however, nuclear atypia has been recorded and said to indicate increased malignant potential. ${ }^{8}$ Cytokeratin positivity has been reported ${ }^{9}$ but is uncommon; however, the pituitary is a relatively common site for metastatic carcinoma from other sites. ${ }^{10}$

\section{Conclusion}

This widespread tumour illustrates the problem of classifying neuroendocrine tumours when there is no obvious primary site. The diagnoses of atypical carcinoid, malignant paraganglioma, and pituitary carcinoma were all considered; however, our favoured diagnosis was atypical carcinoid.

1 Nida TY, Hall WA, Glantz MJ, Clark HB. Metastatic carcinoid tumour to the orbit and brain. Neurosurgery 1992:31:949-52.

2 Patchell RA, Posner JB. Neurologic complications of carcinoid. Neurology 1986;36:745-9.

3 Sonneland PRL, Scheithauer BW, LeChago J, Crawford BG, Onofrio BM. Paraganglioma of the cauda equin region. Clinicopathologic study of 31 cases with special reference to immunocytology and ultrastructure. Cancer 1986;58:1720-35.

4 Lack EE, Cubilla AL, Woodruff JM. Paragangliomas of the head and neck region. A pathologic study of tumours from 71 patients. Hum Pathol 1979;10:191-218.

5 Brodkey JA, Brodkey JS, Watridge CB. Metastatic paraganglioma causing spinal cord compression. Spine 1995;20: glioma

6 Scheithauer BW, Randall RV, Laws ER, Kovacs KT, Horvath E, Whitaker MD. Prolactin cell carcinoma of th pituitary. Clinicopathologic, immunohistochemical, and ultrastructural study of a case with cranial and extracrania metastases. Cancer 1985;55:598-604.

7 Asai A, Matsutani M, Funada N, Takakura K. Malignant growth hormone-secreting pituitary adenoma with haematogenous dural metastasis: case report. Neurosurgery 1988 22:1091-4.

8 Challa VR, Marshall RB, Hopkins MB, Kelly DL, Civantos F. Pathobiologic study of pituitary tumours: report of 62 Fases with a review of the recent literature. Hum Pathol cases with a re
$1985 ; 16: 873-84$

9 Frost AR, Tenner S, Tenner M, Rollhauser C, Tabbara SO. ACTH-producing pituitary carcinoma presenting as the cauda equina syndrome. Arch Pathol Lab Med 1995;119. 93-6.

10 Nudleman KL, Choi B, Kusske JA. Primary pituitary carcinoma: a clinical pathological study. Neurosurgery 1985;16:90-5.
Department of Pathology, Western Infirmary, Glasgow G11 6NT, United

Kingdom

M R Stephen

K Oien

R K Ferrier

R A Burnet

Correspondence to: Dr M R Stephen.

Accepted for publication 26 February 1997

\title{
Effusion cytology of hepatocellular carcinoma with in situ hybridisation for human albumin
}

\author{
M R Stephen, K Oien, R K Ferrier, R A Burnett
}

\begin{abstract}
While the cytological features of hepatocellular carcinoma on fine needle aspiration cytology are well described, cases of hepatocellular carcinoma with malignant cells in ascitic fluid and their characteristics are not. A patient is described with cirrhosis resulting from chronic hepatitis $B$ virus infection, ascites, and hepatocellular carcinoma diagnosed by effusion cytology. The malignant cells in the effusion were shown to be positive for $\alpha$ fetoprotein using immunocytochemistry, and for human albumin using in situ hybridisation, confirming the diagnosis of hepatocellular carcinoma. Further investigations in a terminally ill patient were thus avoided.

(F Clin Pathol 1997;50:442-444)
\end{abstract}

Keywords: ascitic fluid; hepatocellular carcinoma; albumin; in situ hybridisation
Ascites is a common complication of both cirrhosis and hepatocellular carcinoma. The yield of malignant cells from hepatocellular carcinoma is generally low (approximately $10 \%$ in the series described by Falconieri et $\left.a l^{1}\right)$, and they may be more often identified in cases of hepatocellular carcinoma without cirrhosis. ${ }^{1}$ There may be difficulty distinguishing the malignant cells from reactive and atypical mesothelial cells which are commonly seen in effusions from cirrhotic patients. The immunocytochemical staining profile of hepatocellular carcinoma expressing positivity for keratins and negativity for $\mathrm{CEA}^{2}$ does not help to distinguish hepatocellular carcinoma cells from mesothelial cells. Positive staining for $\alpha$ fetoprotein, while helpful, is not specific. ${ }^{1}$ Albumin gene detection by in situ hybridisation is a highly specific aid to the confirmation of the origin of the malignant cells in an effusion. ${ }^{3}$ 


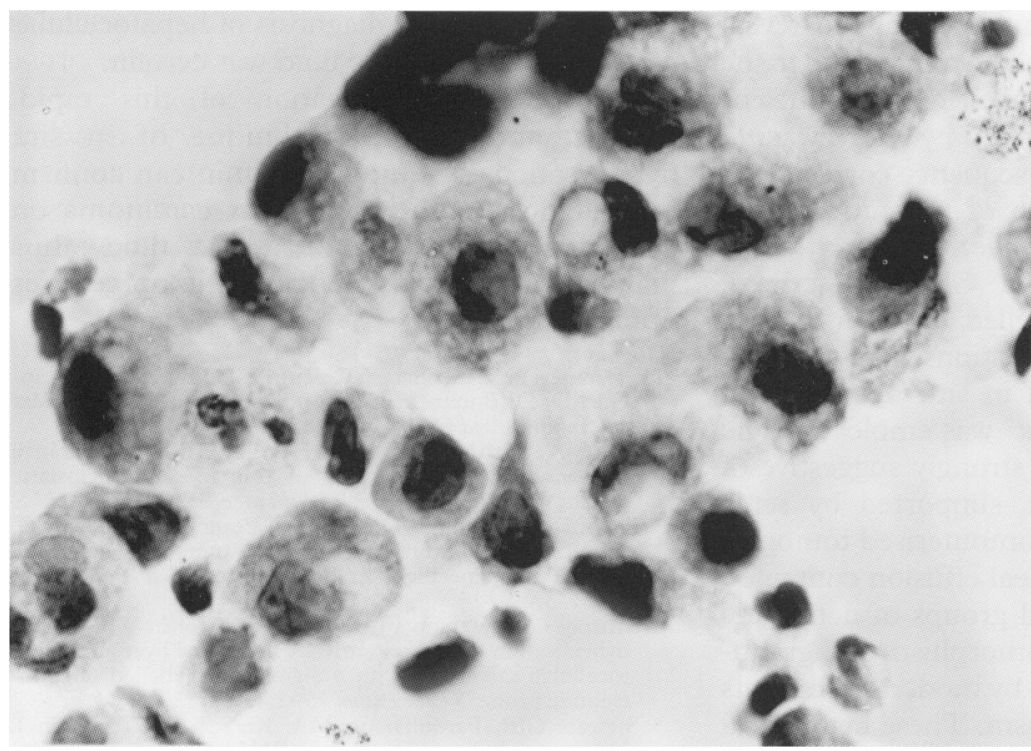

Figure 1 A group of dispersed malignant cells with mildly pleomorphic nuclei and granular chromatin surrounded by moderate amounts of granular cytoplasm containing intracytoplasmic vacuoles some of which were bile droplets. (Cytospin haematoxylin and eosin, $\times 600$.)

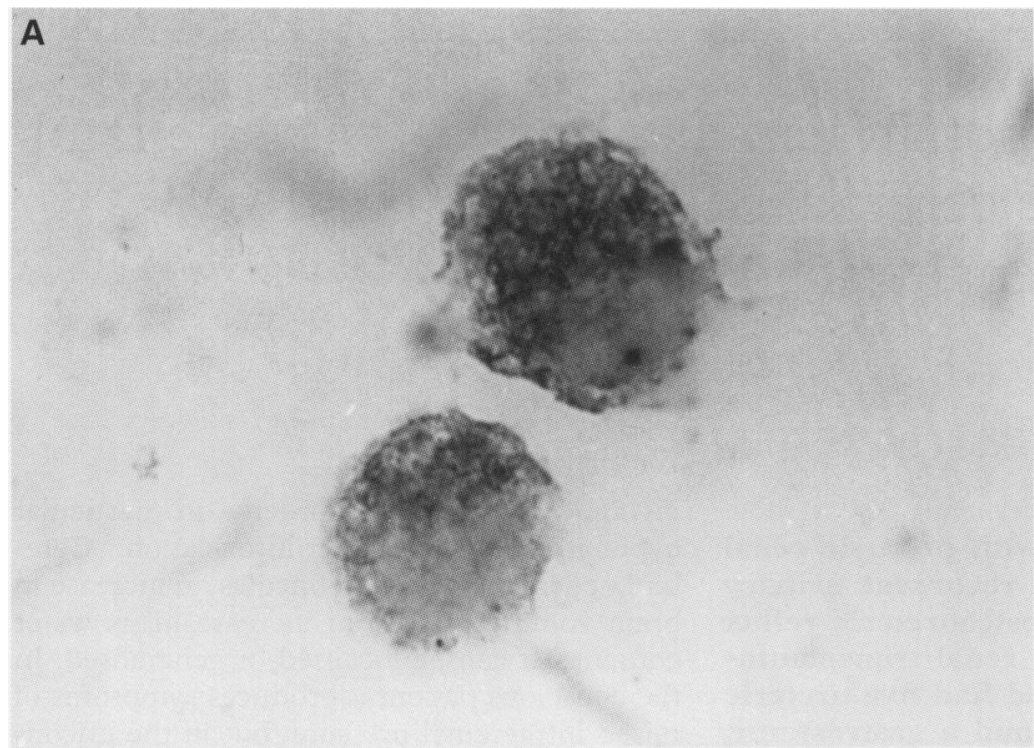

B
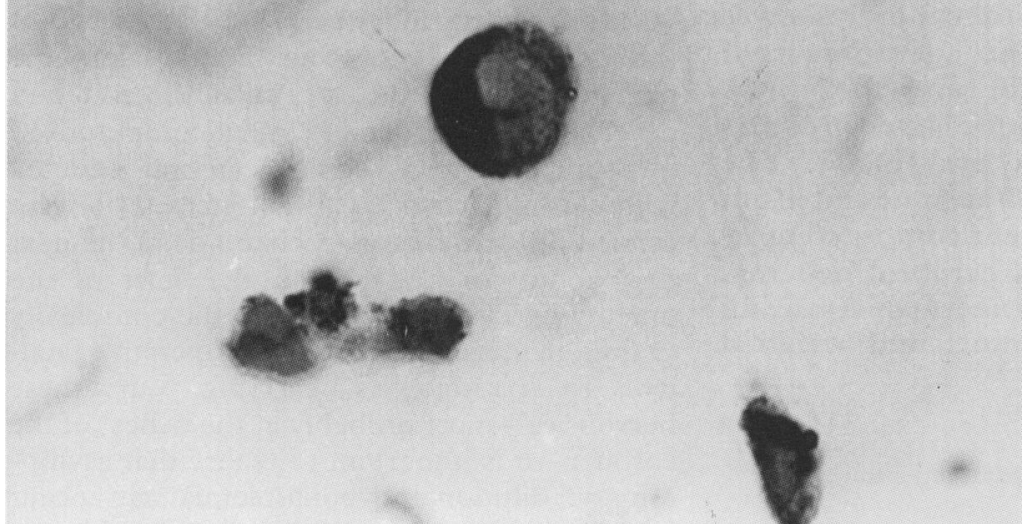

Figure 2 (A) Two malignant cells strongly reacting to a fetoprotein antibody (cytospin AP-Vector $S K-5100, \times 600)$. (B) Strong diffuse cytoplasmic staining for human albumin $m R N A$ in a malignant cell. (The hybridised probe was visualised using nitroblue tetrazolium/bromo-chloro-indolyl-phosphate (NBT/BCIP) substrate. Cytospin $\times 600$.)

\section{Case report}

The patient was a 60 year old woman of Chinese extraction who had made many trips to Hong Kong. She had chronic hepatitis B virus infection ( $\mathrm{HbsAg}$ and $\mathrm{HbeAg}$ positive), which had been diagnosed 18 months before the most recent admission and had been confirmed by liver biopsy, the report of which concluded that although there was some fibrous scarring, cirrhosis was not established. Focal areas of hepatocyte dysplasia, however, were noted. She presented terminally with rapid clinical deterioration with malaise, anorexia, deepening jaundice, and diuretic resistant ascites. Ultrasound and computerised tomography suggested a multicentric hepatocellular carcinoma. Her $\alpha$ fetoprotein serum concentrations were grossly raised at $2070 \mathrm{KU} / 1$ (normal < $5 \mathrm{KU} / \mathrm{l})$. In view of her gross ascites and disturbed coagulation, a repeat liver biopsy was not performed. Paracentesis was done, largely for symptomatic relief. Confirmation of the hepatocellular carcinoma was made from the effusion cytology. In view of the poor prognosis, symptomatic treatment only was continued. Permission for necropsy was refused.

\section{Cytology findings}

Cytospin preparations were made and were moderately cellular. Small lymphocytes and reactive mesothelial cells were present in the background. The malignant cells lay in small groups and as single cells. The nuclei tended to be large and hyperchromatic without prominent nucleoli. The cytoplasm was faintly granular. A striking feature was the presence of small round cytoplasmic vacuoles (fig 1). Some of the vacuoles contained PAS positive material while others stained positively for iron and bile. Many apoptotic cells were noted. The abnormal cells stained strongly on immunocytochemistry with antibodies for $\alpha$ fetoprotein (fig $2 \mathrm{~A}$ ), which is a hepatocellular product but is not absolutely specific for malignant cells from a hepatocellular carcinoma. Albumin is a specific product of normal and transformed hepatocytes. In situ hybridisation for the detection of the albumin gene was strongly positive in this case (fig $2 \mathrm{~B}$ ).

\section{Discussion}

The diagnosis of hepatocellular carcinoma is important because many cases present late and the patients may have systemic problems such as coagulopathy that prevent invasive procedures to obtain diagnostic material. The cytological features on fine needle aspiration of hepatocellular carcinoma are well described, but are of little use when applied to effusion cytology - for example, endothelial rimming of neoplastic cell groups and intranuclear inclusions are not notable features in an ascitic fluid.

Metastatic malignancy-for example from lung or gastrointestinal tract in peritoneal effusions, shows a relatively limited range of cytological expression, and confusion with reactive mesothelial cells can be a disturbing problem. The application of a technique which is specific to the hepatocyte is clearly a great benefit in defining the site of origin of a neoplasm. 
An in situ hybridisation procedure to reveal albumin mRNA on formalin fixed hepatic tissue using a digoxigenin labelled oligonucleotide probe has been developed by Murray et al. ${ }^{4}$ In our case a $2 \mathrm{~kb}$ cDNA sequence corresponding to a coding sequence of human albumin provided by ATCC (Rockville, Maryland, USA) was used to produce a SP6 transcribed, digoxigenin 11 UTP labelled anti-sense riboprobe. The cytospin preparations were formalin fixed and the method of in situ hybridisation developed by Stewart et $a l^{5}$ was employed. The patient had clinical signs strongly suggestive of hepatocellular carcinoma, supported by serological, ultrasound, and computerised tomography findings. The peritoneal effusion contained single neoplastic cells and groups of neoplastic cells showing nuclear pleomorphism and granular chromatin surrounded by moderate amounts of rather granular cytoplasm. These cytological features were certainly in keeping with the appearances of hepatocellular carcinoma as described in fine needle aspirate, ${ }^{6}$ and after demonstrating human albumin mRNA in these cells we felt that the diagnosis of hepatocellular carcinoma in the ascitic fluid was certain.

We feel that application of this rapid, reliable, and specific technique of in situ hybridisation for human albumin can confirm the diagnosis of hepatocellular carcinoma on cytospin preparations of ascitic fluid, thus making further invasive diagnostic procedures unnecessary.

1 Falconieri G, Zanconati F, Colautti I, Dudine S, BonifacioGori D, Di Bonito L. Effusion cytology of hepatocellula carcinoma. Acta Cytol 1995;39:893-7.

$2 \mathrm{Ma} \mathrm{C-K,} \mathrm{Zarbo} \mathrm{RJ,} \mathrm{Frierson} \mathrm{HF,} \mathrm{Lee} \mathrm{MW.} \mathrm{Comparative}$ immunohistochemical study of primary and metastatic carcinoma of the liver. Am f Clin Pathol 1993;99:551-7.

3 Papotti M, Pacchioni D, Negro F, Bonino F, Bussolati G. Albumin gene expression in liver tumours: diagnostic interest in fine needle aspiration biopsies. Mod Pathol 1994; 7:271-5.

4 Murray GI, Paterson PJ, Ewen SWB, Melvin WT. In situ hybridisation of albumin mRNA in normal liver and hepatocellular carcinoma with a digoxigenin labelled oligonutocellular carcinoma with a digoxigenin
cleotide probe. $\mathrm{f}$ Clin Pathol 1992;45:21.

5 Stewart CJR, Farquharson MA, Kerr T, McCorriston J. Immunoglobulin light chain mRNA detected by in situ hybridisation in diagnostic fine needle aspiration cytology specimens. F Clin Pathol 1996;49:749-53.

6 Pilotti S, Rilke F, Claren R, Milellan M, Lombardi L. Conclusive diagnosis of hepatic and pancreatic malignancies by fine needle aspiration. Acta Cytol 1988;32:27-38.

\title{
Dilutional hyponatraemia: a cause of massive fatal intraoperative cerebral oedema in a child undergoing renal transplantation
}

\author{
A Armour
}

\begin{abstract}
A four year old boy with polyuric renal failure resulting from recurrent urinary tract infections and vesicoureteric reflux from birth underwent renal transplantation. In the past he had had five ureteric reimplant operations and a gastrostomy, as he ate nothing by mouth. He required peritoneal dialysis 13 hours a night, six nights a week. His fluid requirements were $2100 \mathrm{ml}$ per day. This included a night feed of 1.5 litres Nutrizon. Before operation he received $900 \mathrm{ml}$ of Dioralyte instead of the Nutrizon feed, and peritoneal dialysis was performed as usual. The operation itself was technically difficult and there was more blood loss than anticipated, requiring intravenous fluids and blood. The operation ended about four hours later but he did not wake up. Urgent computed tomography revealed gross cerebral oedema. He died the next day. At necropsy the brain was massively oedematous and weighed $1680 \mathrm{~g}$.

(f Clin Pathol 1997;50:444-446)
\end{abstract}

Keywords: cerebral oedema; operation; intravenous fluids

There are various causes of cerebral oedema including inflammatory conditions, ischaemia, trauma, space occupying lesions, anoxia, tox- ins, and metabolic disorders-in particular hyponatraemia ${ }^{1}$ and water intoxication. ${ }^{2}$ Cerebral oedema has been defined as an increase in brain volume due to an increase in its water content. ${ }^{3}$ It can be localised or generalised. In the conscious patient it produces symptoms of raised intracranial pressure, but in the unconscious the symptoms are masked. Cerebral oedema developing as a result of hyponatraemia is well documented ${ }^{4-6}$ but most of these cases have developed postoperatively or following intravenous administration of fluids in a conscious patient. The event described here occurred during anaesthesia, and at the end of the operation-about four hours later-the patient, a child, did not wake up and had developed papilloedema. Urgent computerised tomography showed gross cerebral oedema with slit-like ventricles. Brain stem tests were carried out and he was declared dead the next day, about 26 hours from the start of the operation. This case illustrates the complexity of fluid management in an intraoperative fatality. To pathologists carrying out these necropsies - most probably at the behest of the coroner-it is important to realise that asymptomatic dilutional hyponatraemia can occur intraoperatively when the symptoms of hyponatraemia and cerebral oedema are masked due to anaesthesia and unconsciousness. Arieff $e t \mathrm{al}^{4}$ studied 16 cases of symptomatic postoperative 